\title{
Two key messages were overlooked in article on personal health budgets
}

\author{
Martin McKee professor of European public health
}

London School of Hygiene and Tropical Medicine, London WC1H 9SH, UK

It was unfortunate that Chinthapalli overlooked the key message of our paper on the Dutch experience with personal health budgets - that their availability is being scaled back radically because of escalating costs and widespread abuse. ${ }^{12}$

Another key issue was overlooked. Many view personal health budgets as the beginning of a process, initiated by the Health and Social Care Bill, whereby at some point in the future each of us will be allocated a fixed amount to purchase insurance, with the requirement to top up anything that is not covered. This would be consistent with views expressed previously by various Conservative politicians. ${ }^{3}$ What may seem like a good idea could easily become a Trojan horse.
Competing interests: None declared.

Chinthapalli K. Personal health budgets: surplus of cash or deficit of ideas? BMJ 2012;345:e8329. (10 December.)

2 Van Ginneken E, Groenewegen PP, McKee M. Personal healthcare budgets: what can England learn from the Netherlands? BMJ 2012;344:e1383.

3 Reynolds L, McKee M. Opening the oyster: the 2010-2011 NHS reforms in England. Clin Med 2012;12:128-32.

Cite this as: BMJ 2013;346:f34

(c) BMJ Publishing Group Ltd 2013 